\title{
Alcohol Drinking and Cognitive Functions: Findings from the Cardiovascular Risk Factors Aging and Dementia (CAIDE) Study
}

\author{
Tiia Ngandu ${ }^{a, b}$ Eeva-Liisa Helkala ${ }^{c}$ Hilkka Soininen $^{b}$ Bengt Winblad $^{a, d}$ \\ Jaakko Tuomilehto ${ }^{\mathrm{e}-\mathrm{g}} \quad$ Aulikki Nissinen $^{\mathrm{e}}$ Miia Kivipelto ${ }^{\mathrm{a}, \mathrm{b}, \mathrm{d}}$

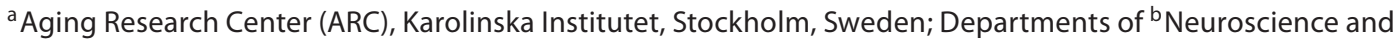 \\ Neurology and 'Public Health and General Practice, University of Kuopio, Kuopio, Finland; ${ }^{d}$ Division of Geriatric

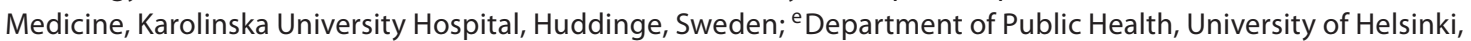

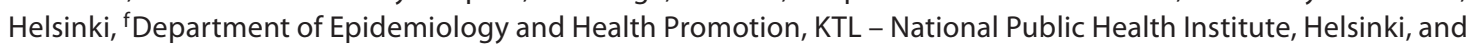 \\ ${ }^{g}$ South Ostrobothnia Central Hospital, Seinäjoki, Finland
}

\section{Key Words}

Alcohol drinking, cognitive function - Cognitive function, alcohol consumption · Cohort studies, alcohol drinking

\begin{abstract}
Background: Moderate alcohol drinking is suggested to be beneficial for cognitive functions, but the results of previous studies have varied greatly. Little is known about the effects of midlife alcohol drinking on the cognitive functions later in life. Methods: Participants were derived from random, population-based samples studied in Eastern Finland in $1972,1977,1982$, or 1987. A total of 1,341 participants were reexamined in 1998, after an average follow-up period of 21 years, at ages 65-79 years. Results: The participants who did not drink alcohol at midlife had a poorer performance in episodic memory, psychomotor speed, and executive function in late life as compared with infrequent and frequent drinkers, adjusted for sociodemographic and vascular factors. Also late-life nondrinkers had poorer psychomotor speed and executive function. These findings were evident especially among nonsmokers. Further, no interactions between apolipoprotein $\mathrm{E} 4$ and alcohol or sex and alcohol were found. Conclusions: Alcohol drinking both at midlife and later is
\end{abstract}

favorably related to the function in several cognitive domains, including episodic memory, psychomotor speed, and executive function, in late life. However, it is not clear whether the association is causal, what is the possible mechanism, and what would be a safe limit of drinking for the best cognitive function.

Copyright $\odot 2007$ S. Karger AG, Basel

\section{Introduction}

Several cognitive functions, such as psychomotor speed, executive function, and episodic memory, decline with aging. Other functions, including semantic memory, remain fairly intact $[1,2]$. Identification of the determinants of the individual differences in cognitive functions has been much in the focus of research. As alcohol drinking is in many societies a common habit, the effects it may have on cognition might have a great public health importance, especially in terms of the prevention of cognitive impairment.

The studies that have assessed changes in cognition prospectively have had contradictory results. Drinkers have been proposed to have a greater decrease in global

\section{KARGER \\ Fax +41613061234 E-Mail karger@karger.ch} www.karger.com
(C) 2007 S. Karger AG, Basel

$1420-8008 / 07 / 0233-0140 \$ 23.50 / 0$

Accessible online at: www.karger.com/dem
Tiia Ngandu

Aging Research Center, Karolinska Institutet

Gävlegatan 16

SE-11330 Stockholm (Sweden)

Tel. +46 35840524 1759, Fax +46 35817162 048, E-Mail tiia.ngandu@ki.se 
cognitive function [3] or attention [4] as compared with nondrinkers, but moderate drinkers to have less decline in cognition $[5,6]$ or psychomotor speed [7] than nondrinkers. Further, some studies $[8,9]$ showed no association at all. The associations between current cognitive performance and alcohol drinking 5-20 years earlier have also been studied, with varying results: the global cognitive function may be poorer among both alcoholics and past drinkers as compared with nondrinkers or moderate drinkers [10] and better among moderate drinkers and poorer among heavy drinkers as compared with nondrinkers [11]. Further, psychomotor flexibility and speed may be better among moderate drinkers, but the memory was better among heavy drinkers than among nondrinkers [12]. In several cross-sectional studies, moderate alcohol drinking as compared with nondrinking has been associated with a better function in many cognitive domains [13-16]. On the other hand, both better [16-18] and poorer [14] cognitive performances with higher levels of alcohol drinking have been observed. At the same time, a number of studies have found no associations between alcohol drinking and several cognitive functions $[15,17,19,20]$. Further, alcohol drinking is one of the possible determinants of clinical dementia [21-23].

Studies on the interaction between smoking and alcohol drinking have yielded inconclusive results $[4,19]$. Further, a significant association between alcohol drinking and several cognitive measures has been proposed especially among women $[12,15,17]$. The role of alcohol for the cognition might be modified by the presence of the apolipoprotein E allele epsilon 4 (ApoE4) [3, 13], but the patterns of interaction suggested have been different. One study investigating the effect of different types of alcohol on the cognitive function found no beverage-specific differences [10].

The results of the previous studies on alcohol drinking and cognition have varied greatly, and studies with long follow-up periods are few. It is possible that over time, and maybe associated with the cognitive decline, alcohol drinking will change, and, therefore, long-term followup studies are needed to clarify the issue. In our previous study [21], we have shown that midlife alcohol drinking was associated with an increased risk of dementia, especially among the ApoE4 carriers. The aim of our current study was to investigate whether alcohol drinking in midlife is associated with the cognitive functions later on in a nondemented population of elderly persons. We also evaluated which aspects of the cognitive function were most associated with alcohol and whether smoking, sex, or ApoE4 would modify the association between alcohol drinking and cognitive functions. In the secondary analyses, we investigated also whether there were beveragespecific differences.

\section{Subjects and Methods}

\section{Study Participants}

The participants of the Cardiovascular Risk Factors Aging and Dementia (CAIDE) study were derived from random population-based samples in two geographical areas in Eastern Finland. They were first studied in 1972, 1977, 1982, or 1987 within the framework in North Karelia Project and FINMONICA Study [24]. The participation rates of these surveys were around 90\%. A random sample of 2,000 survivors aged from 65 to 79 years in 1997 were invited for reexamination in 1998 [25]. Altogether 1,409 of these subjects $(70.5 \%)$ completed the reexamination. The population of the present study comprised 1,341 nondemented participants (68 demented persons were excluded) at follow-up: 835 women $(62.3 \%)$ and 506 men $(37.7 \%)$. The mean age (SD) of the population was $50.2(6.0)$ years at the time of the midlife examination and 71.1 (4.0) years at the follow-up examination. Due to the differences in alcohol-related questions between different baseline years, our main analyses are focused on the persons who were first included in 1972/1977 ( $\mathrm{n}=972)$. In the secondary analyses regarding different alcoholic beverages, the sample of persons included in 1982/1987 $(n=369)$ was used. Six persons were excluded due to missing alcohol information from the main analyses (1972/1977) and 56 persons from the secondary analyses (1982/1987). The ethics committees of the University of Kuopio and the Kuopio University Hospital, Kuopio, Finland, approved the study. Written informed consent was obtained from all participants in 1998.

\section{Methods}

The survey methods used during the baseline (midlife) visit were standardized following international recommendations [26]. The survey included a self-administered questionnaire on health behavior, health status, medical history, and socioeconomic factors. Blood pressure, height, and weight were measured, and a venous blood specimen was taken. During the reexamination in 1998 , the survey methods followed those utilized in the previous surveys. Additionally, the ApoE genotype was determined [27] and the cognitive status assessed [25].

\section{Measurement of Alcohol Drinking}

The questions concerning alcohol drinking varied between the different baseline sampling years. In the 1972 and 1977 questionnaires $(n=966)$, the frequency of overall alcohol drinking was determined. People were classified into three groups: those who never drank alcohol (referred to as 'never'), those who drank less frequently than once per month ('infrequent'), and those who drank once per month or more often ('frequent'). Furthermore, the effect of change in drinking between midlife and late life was analyzed by grouping the persons into all nine possible classes, i.e., never drinker in midlife and never drinker in late life, etc. In the 1982 and 1987 questionnaires $(n=313)$, the consumption of beer, wine, spirits, and 'soft drink mixes' during the previous week was inquired. This was used to evaluate the effect of spe- 
cific beverages. Furthermore, the total weekly alcohol intake (g/ week) was determined. The people were divided into three categories (nondrinkers, drinkers divided into two groups at the median) to allow for nonlinear effects. In the calculations, the following alcohol contents were used: a bottle of beer containing $12.5 \mathrm{~g}$ of alcohol, a glass of wine containing $12 \mathrm{~g}$, a drink of spirits containing $12 \mathrm{~g}$, and a 'soft drink mix' containing $14.5 \mathrm{~g}$ of alcohol. In the follow-up examination in 1998, the questions were comparable to those of the baseline years, but additionally, the weekly consumption of cider/light wine (alcohol content $6 \mathrm{~g}$ ) was queried, and a question on whether a person had quit drinking any time prior to the 1998 examination was included.

\section{Measurement of the Cognitive Functions}

All participants were proposed a battery of cognitive tests in the late-life examination. The Mini-Mental State Examination (MMSE) [28] was administered to measure the global cognitive function (12 subjects had missing information on MMSE). The episodic memory was assessed with a test of immediate word recall $[29,30]$ (18 subjects missing). The mean number of the correct words in three different word lists of 10 words was calculated. The semantic memory was assessed with the category fluency test [31] (10 subjects missing). The score was the number of correct animal names generated within $60 \mathrm{~s}$. The psychomotor speed was analyzed using the sum of the normalized scores in the bimanual Purdue Pegboard Test [32] and the letter digit substitution test [33] (100 subjects missing). The correlation between the two tests was $r=0.479(p<0.001)$ which indicated that they are measuring the same dimension. Executive function was defined as the difference in the time used in the Stroop trial of naming the color of the ink used to write the name of another color and the trial of naming colors of dots [34] (69 subjects missing). In the prospective memory task [35], at the beginning of the test session, the subjects were asked to remind the investigator that he/she must sign a paper at the end of the test session (174 subjects missing). The scores in the test were: remembering without reminder (score $=4)$, remembering with one reminder (score $=3$ ), remembering with two reminders (score $=2$ ), or not remembering (score $=1$ ). Subjective memory was defined as a mean result of 22 questions [36], all ranging from one to four, with four being the lowest subjective memory (19 subjects missing).

\section{Statistics}

The bivariate comparisons of the characteristics of the participants were done using $\chi^{2}$ test, $t$ test, and analysis of variance, as appropriate. To analyze the effect of alcohol drinking on cognition, analysis of covariance models were used for all cognitive tests, with Bonferroni adjustments for multiple comparisons. The analyses were first adjusted for age, sex, education, and follow-up time and, additionally, also for midlife vascular factors (systolic blood pressure, body mass index, total cholesterol level, smoking status), ApoE4 carrier status, late-life history of myocardial infarction, stroke and diabetes, late-life living status (alone/with partner), income level (lower/higher), and depressive symptoms [37]. We tested for interactions between alcohol drinking and smoking, sex, and ApoE4 by including the interaction terms into the model as well as by carrying out analyses stratified by smoking, sex, and ApoE4 status. The statistical analyses were conducted with the SPSS for Windows, version 12.0.1 (SPSS, Chicago, Ill., USA).

\section{Results}

Characteristics of the Study Participants according to Their Alcohol Drinking Frequency at Midlife

(1972 and 1977)

Approximately $30 \%$ of the participants did not drink alcohol at the time of the midlife examination, $40 \%$ drank infrequently, and $30 \%$ drank frequently (table 1). The never drinkers were older, less educated, and more often women. Smoking was more prevalent among frequent alcohol drinkers and among men (76\%), whereas among women, only $23 \%$ were smokers. In late life, the midlife never drinkers more often belonged to the lower income category and lived alone and had higher scores on the Beck Depression Inventory.

\section{Alcohol Drinking Frequency at Midlife (1972 and \\ 1977) and Late Life (1998) Examinations and \\ Cognitive Function in Late Life}

In the fully adjusted analyses among all participants, never drinkers at midlife performed significantly poorer than infrequent and frequent drinkers in episodic memory, executive function, and psychomotor speed in late life (table 2). Never drinkers at midlife also performed poorer than frequent drinkers in prospective memory. In the cross-sectional analyses, the never drinkers in late life performed poorer than the other two groups in executive function and psychomotor speed and poorer than frequent drinkers in episodic and prospective memory. Furthermore, the infrequent drinkers in late life performed poorer than frequent drinkers in episodic and prospective memory. Exclusion of those who reported having quit drinking $(\mathrm{n}=86)$ at any time prior to the 1998 examination did not change the results.

In the analyses carried out separately among smokers and nonsmokers, we found that significant results were mostly seen among nonsmokers (table 3 ). No differences in cognition according to the midlife drinking frequency were seen among smokers. There were significant interactions between midlife alcohol drinking frequency and smoking in episodic memory $(\mathrm{p}=0.01)$ and psychomotor speed $(\mathrm{p}=0.01)$; the cognitive performance increased with increasing alcohol drinking frequency among nonsmokers, while among smokers there was no association. Among smokers, there was a poorer performance in prospective memory among late-life infrequent drinkers as compared with frequent drinkers $(\mathrm{p}=0.01)$. There were no significant interactions between the late-life drinking frequency and smoking.
Ngandu/Helkala/Soininen/Winblad/ Tuomilehto/Nissinen/Kivipelto 
Table 1. Comparison of the characteristics of the participants according to the midlife alcohol consumption frequency (sample 1972/1977)

\begin{tabular}{|c|c|c|c|c|}
\hline & \multicolumn{3}{|c|}{ Midlife alcohol drinking } & \multirow[t]{2}{*}{$\mathrm{p}^{1}, \mathrm{p}^{2}, \mathrm{p}^{3 \mathrm{~b}}$} \\
\hline & $\begin{array}{l}\text { never } \\
(\mathrm{n}=285 ; 29.5 \%)\end{array}$ & $\begin{array}{l}\text { infrequent } \\
(\mathrm{n}=403 ; 41.7 \%)\end{array}$ & $\begin{array}{l}\text { frequent } \\
(\mathrm{n}=278 ; 28.8 \%)\end{array}$ & \\
\hline Age at baseline, years & $48.3(4.9)$ & $47.6(4.9)$ & $47.5(4.5)$ & $\mathrm{p}^{1}=0.07, \mathrm{p}^{2} 0=0.04$ \\
\hline Age at follow-up, years & $72.1(4.0)$ & $71.2(4.0)$ & $70.6(3.8)$ & $\mathrm{p}^{1}=0.00, \mathrm{p}^{2} 0=0.00, \mathrm{p}^{3}=0.04$ \\
\hline Follow-up time, years & $23.8(2.5)$ & $23.6(2.5)$ & $23.1(2.4)$ & $\mathrm{p}^{2}=0.00, \mathrm{p}^{3}=0.01$ \\
\hline Education, years & $8.3(3.3)$ & $8.9(3.3)$ & $9.1(3.7)$ & $\mathrm{p}^{1}=0.04, \mathrm{p}^{2} 0=0.00$ \\
\hline Females/males, $\%^{\mathrm{a}}$ & $83.5 / 16.5$ & $64.5 / 35.5$ & $37.4 / 62.6$ & $\mathrm{p}^{1}=0.00, \mathrm{p}^{2} 0=0.00, \mathrm{p}^{3}=0.00$ \\
\hline Number of ApoE E4 carriers (\%) & $108(39.0)$ & $134(34.1)$ & $92(33.7)$ & \\
\hline \multicolumn{5}{|l|}{ Baseline (midlife) } \\
\hline Systolic blood pressure, $\mathrm{mm} \mathrm{Hg}$ & $143.6(20.3)$ & $142.1(19.3)$ & $142.9(17.8)$ & \\
\hline Diastolic blood pressure, $\mathrm{mm} \mathrm{Hg}$ & $90.1(10.1)$ & $89.3(10.8)$ & 90.7 (10.9) & $\mathrm{p}^{3}=0.10$ \\
\hline Total cholesterol, $\mathrm{mmol} / \mathrm{l}$ & $6.88(1.26)$ & $6.69(1.26)$ & $6.75(1.11)$ & $\mathrm{p}^{1}=0.06$ \\
\hline Body mass index, $\mathrm{kg} / \mathrm{m}^{2}$ & $26.5(3.7)$ & $26.0(3.6)$ & $26.3(3.3)$ & $\mathrm{p}^{1}=0.03$ \\
\hline Number of smokers $(\%)^{\mathrm{a}}$ & $52(18.2)$ & $186(46.3)$ & $191(68.7)$ & $\mathrm{p}^{1}=0.00, \mathrm{p}^{2} 0=0.00, \mathrm{p}^{3}=0.00$ \\
\hline \multicolumn{5}{|l|}{ Follow-up (late life) } \\
\hline Number with lower income $(\%)^{\mathrm{a}}$ & $137(50.7)$ & $148(38.5)$ & $93(35.0)$ & $\mathrm{p}^{1}=0.00, \mathrm{p}^{2} 0=0.00$ \\
\hline Number living alone $(\%)^{\mathrm{a}}$ & $144(50.9)$ & $151(37.9)$ & $93(33.5)$ & $\mathrm{p}^{1}=0.00, \mathrm{p}^{2} 0=0.00$ \\
\hline Beck Depression Inventory score & $10.4(6.7)$ & $8.9(5.9)$ & $9.5(7.1)$ & $\mathrm{p}^{1}=0.01$ \\
\hline Number with diabetes (\%) & $17(5.8)$ & $23(5.9)$ & $20(7.4)$ & \\
\hline Number with myocardial infarction $\%)^{\mathrm{a}}$ & $38(13.5)$ & $54(13.7)$ & $49(17.8)$ & \\
\hline Number with stroke $(\%)^{\mathrm{a}}$ & $18(6.5)$ & $28(7.2)$ & $13(4.8)$ & \\
\hline
\end{tabular}

Mean values (SD) are presented unless otherwise stated; ANOVA was used unless otherwise indicated.

${ }^{\mathrm{a}} \chi^{2}$ test was used.

${ }^{b} \mathrm{p}^{1}$ is the $\mathrm{p}$ value for the difference between never and infrequent drinkers; $\mathrm{p}^{2}$ for the difference between never and frequent drinkers, and $\mathrm{p}^{3}$ for the difference between infrequent and frequent drinkers. Only $\mathrm{p}$ values $\leq 0.10$ are given.

Among women, the never drinkers at midlife had a poorer episodic memory and psychomotor speed as compared with infrequent and frequent drinkers in the fully adjusted model (results not shown). Among men, there was a poorer executive function among midlife never drinkers as compared with the other groups. Regarding late-life alcohol drinking, women who were never drinkers had poorer episodic memory and psychomotor speed as compared with frequent drinkers. Among men, never drinkers in late life had a poorer executive function as compared with frequent drinkers, and the infrequently drinking men had a poorer episodic, semantic, and prospective memory as compared with frequent drinkers. There were no significant interactions between sex and alcohol drinking frequency.

The analyses stratified by the presence of ApoE4 allele showed that the associations between midlife alcohol drinking frequency and episodic memory, executive function, and psychomotor speed were similar to those of the main analyses, but significant only among the ApoE4 noncarriers in the fully adjusted model (results not shown). An association between late-life drinking frequency and psychomotor function was found among the ApoE4 noncarriers. However, there were no significant interactions between the ApoE4 status and the alcohol drinking frequency at midlife or in late life for the cognitive functions studied.

Most of the persons reported a similar drinking frequency both at midlife and late-life examinations. Those that were never drinkers on both occasions had a poorer performance in episodic memory as compared with those that reported infrequent or frequent drinking at midlife and frequent drinking in late life (table 4). Never drinkers at both examinations had also poorer results in psychomotor speed as compared with those who were infrequent drinkers at midlife and infrequent or frequent drinkers in late life or with those who were frequent drinkers on both occasions. In the majority of the tests, those who were frequent drinkers at midlife but nondrinkers in late life had the poorest results, but the differ- 
Table 2. Cognitive functioning in late life in relation to the midlife and late-life alcohol drinking frequency (sample 1972/1977)

\begin{tabular}{|c|c|c|c|c|c|c|c|c|}
\hline & \multicolumn{4}{|c|}{ Midlife alcohol drinking } & \multicolumn{4}{|c|}{ Late-life alcohol drinking } \\
\hline & $\begin{array}{l}\text { never } \\
(\mathrm{n}=285)\end{array}$ & $\begin{array}{l}\text { infrequent } \\
(\mathrm{n}=403)\end{array}$ & $\begin{array}{l}\text { frequent } \\
(\mathrm{n}=278)\end{array}$ & $\mathrm{p}^{1}, \mathrm{p}^{2 \mathrm{a}}$ & $\begin{array}{l}\text { never } \\
(\mathrm{n}=265)\end{array}$ & $\begin{array}{l}\text { infrequent } \\
(\mathrm{n}=326)\end{array}$ & $\begin{array}{l}\text { frequent } \\
(\mathrm{n}=363)\end{array}$ & $\mathrm{p}^{1}, \mathrm{p}^{2}, \mathrm{p}^{3 \mathrm{a}}$ \\
\hline Global cognitive functioning & $26.0(0.1)$ & $26.2(0.1)$ & $26.3(0.1)$ & & $26.0(0.1)$ & $26.0(0.1)$ & $26.3(0.1)$ & \\
\hline Episodic memory & $4.9(0.1)$ & $5.2(0.1)$ & $5.2(0.1)$ & $\begin{array}{l}\mathrm{p}^{1}=0.02 \\
\mathrm{p}^{2}=0.04\end{array}$ & $4.9(0.1)$ & $5.0(0.1)$ & $5.2(0.1)$ & $\begin{array}{l}\mathrm{p}^{2}=0.02 \\
\mathrm{p}^{3}=0.06\end{array}$ \\
\hline Semantic memory & $19.7(0.4)$ & $20.9(0.3)$ & $20.7(0.4)$ & $\mathrm{p}^{1}=0.08$ & $20.4(0.4)$ & $20.0(0.4)$ & $21.0(0.4)$ & \\
\hline Subjective memory & $2.1(0.0)$ & $2.1(0.0)$ & $2.1(0.0)$ & & $2.1(0.0)$ & $2.1(0.0)$ & $2.1(0.0)$ & \\
\hline Prospective memory & $2.6(0.1)$ & $2.8(0.0)$ & $2.8(0.1)$ & $\mathrm{p}^{2}=0.05$ & $2.6(0.1)$ & $2.7(0.1)$ & $2.9(0.0)$ & $\begin{array}{l}\mathrm{p}^{2}=0.01 \\
\mathrm{p}^{3}=0.02\end{array}$ \\
\hline Executive function & $44.0(1.4)$ & $37.2(1.1)$ & $38.1(1.4)$ & $\begin{array}{l}\mathrm{p}^{1}=0.00 \\
\mathrm{p}^{2}=0.01\end{array}$ & $43.0(1.5)$ & $37.8(1.2)$ & $38.5(1.2)$ & $\begin{array}{l}\mathrm{p}^{1}=0.02 \\
\mathrm{p}^{2}=0.06\end{array}$ \\
\hline Psychomotor speed & $-0.04(0.1)$ & $0.19(0.0)$ & $0.19(0.0)$ & $\begin{array}{l}\mathrm{p}^{1}=0.00 \\
\mathrm{p}^{2}=0.01\end{array}$ & $-0.02(0.1)$ & $0.14(0.1)$ & $0.20(0.0)$ & $\begin{array}{l}\mathrm{p}^{1}=0.06 \\
\mathrm{p}^{2}=0.01\end{array}$ \\
\hline
\end{tabular}
ses.

Values are adjusted mean scores (SE) from covariance analy-

${ }^{a} \mathrm{p}^{1}$ is the $\mathrm{p}$ value for the difference between never and infrequent drinkers; $\mathrm{p}^{2}$ for the difference between never and frequent drinkers, and $\mathrm{p}^{3}$ for the difference between infrequent and frequent drinkers. In the cognitive tests used, the higher result means a better performance, except for the subjective memory and executive function, where the lowest result is the best performance. Bonferroni adjustment was used for multiple comparisons. Only p values $\leq 0.10$ are given. Model adjusted for age, sex, education, follow-up time, ApoE4 carrier status, midlife vascular factors (systolic blood pressure, body mass index, total serum cholesterol, smoking), and late-life income, marital status, depression, and history of myocardial infarction, stroke, and diabetes mellitus.

Table 3. Cognitive functioning in late life in relation to the midlife and late-life alcohol drinking frequency among nonsmokers (sample 1972/1977)

\begin{tabular}{|c|c|c|c|c|c|c|c|c|}
\hline & \multicolumn{4}{|c|}{ Midlife alcohol drinking } & \multicolumn{4}{|c|}{ Late-life alcohol drinking } \\
\hline & $\begin{array}{l}\text { never } \\
(\mathrm{n}=233)\end{array}$ & $\begin{array}{l}\text { infrequent } \\
(\mathrm{n}=216)\end{array}$ & $\begin{array}{l}\text { frequent } \\
(\mathrm{n}=87)\end{array}$ & $\mathrm{p}^{1}, \mathrm{p}^{2 \mathrm{a}}$ & $\begin{array}{l}\text { never } \\
(\mathrm{n}=191)\end{array}$ & $\begin{array}{l}\text { infrequent } \\
(\mathrm{n}=188)\end{array}$ & $\begin{array}{l}\text { frequent } \\
(\mathrm{n}=153)\end{array}$ & $\mathrm{p}^{1}, \mathrm{p}^{2 \mathrm{a}}$ \\
\hline Global cognitive functioning & $25.8(0.2)$ & $26.3(0.2)$ & $26.6(0.2)$ & $\begin{array}{l}\mathrm{p}^{1}=0.10 \\
\mathrm{p}^{2}=0.04\end{array}$ & $26.0(0.2)$ & $26.3(0.2)$ & $26.3(0.2)$ & \\
\hline Episodic memory & $4.9(0.1)$ & $5.4(0.1)$ & $5.4(0.1)$ & $\begin{array}{l}\mathrm{p}^{1}=0.00 \\
\mathrm{p}^{2}=0.01\end{array}$ & $5.0(0.1)$ & $5.2(0.1)$ & $5.4(0.1)$ & $\mathrm{p}^{2}=0.00$ \\
\hline Semantic memory & $19.7(0.5)$ & $21.8(0.5)$ & $21.0(0.7)$ & $\mathrm{p}^{1}=0.00$ & $20.3(0.5)$ & $20.7(0.5)$ & $21.2(0.5)$ & \\
\hline Subjective memory & $2.1(0.0)$ & $2.1(0.0)$ & $2.1(0.0)$ & & $2.1(0.0)$ & $2.1(0.0)$ & $2.1(0.0)$ & \\
\hline Prospective memory & $2.7(0.1)$ & $2.9(0.0)$ & $2.9(0.1)$ & $\mathrm{p}^{1}=0.06$ & $2.7(0.1)$ & $2.8(0.1)$ & $2.9(0.1)$ & \\
\hline Executive function & $45.4(1.7)$ & $36.6(1.7)$ & $38.5(2.5)$ & $\begin{array}{l}\mathrm{p}^{1}=0.00 \\
\mathrm{p}^{2}=0.08\end{array}$ & $44.2(1.8)$ & $38.5(1.6)$ & $37.9(1.7)$ & $\begin{array}{l}\mathrm{p}^{1}=0.05 \\
\mathrm{p}^{2}=0.04\end{array}$ \\
\hline Psychomotor speed & $0.03(0.1)$ & $0.31(0.1)$ & $0.45(0.1)$ & $\begin{array}{l}\mathrm{p}^{1}=0.00 \\
\mathrm{p}^{2}=0.00\end{array}$ & $0.03(0.1)$ & $0.23(0.1)$ & $0.33(0.1)$ & $\begin{array}{l}\mathrm{p}^{1}=0.06 \\
\mathrm{p}^{2}=0.00\end{array}$ \\
\hline
\end{tabular}
ses.

Values are adjusted mean scores (SE) from covariance analy-

${ }^{a} \mathrm{p}^{1}$ is the $\mathrm{p}$ value for the difference between never and infrequent drinkers and $\mathrm{p}^{2}$ for the difference between never and frequent drinkers. In the cognitive tests used, the higher result means a better performance, except for the subjective memory and executive function, where the lowest result is the best performance.
Bonferroni adjustment was used for multiple comparisons. Only $\mathrm{p}$ values $\leq 0.10$ are given. Model adjusted for age, sex, education, follow-up time, ApoE4 carrier status, and midlife vascular factors (systolic blood pressure, body mass index, total serum cholesterol, smoking) and late-life income, marital status, depression, and history of myocardial infarction, stroke, and diabetes mellitus. 
Table 4. Changes in the drinking frequency between midlife and late life and the cognitive function in late life (sample 1972/1977)

\begin{tabular}{|c|c|c|c|c|c|c|c|c|c|}
\hline & \multicolumn{9}{|c|}{ Drinking frequency: midlife } \\
\hline & \multicolumn{3}{|l|}{ never } & \multicolumn{3}{|l|}{ infrequent } & \multicolumn{3}{|l|}{ frequent } \\
\hline & \multicolumn{9}{|c|}{ Drinking frequency: late life } \\
\hline & $\begin{array}{l}\text { never } \\
(\mathrm{n}=178)\end{array}$ & $\begin{array}{l}\text { infrequent } \\
(\mathrm{n}=73)\end{array}$ & $\begin{array}{l}\text { frequent } \\
(\mathrm{n}=26)\end{array}$ & $\begin{array}{l}\text { never } \\
(n=63)\end{array}$ & $\begin{array}{l}\text { infrequent } \\
(\mathrm{n}=184)\end{array}$ & $\begin{array}{l}\text { frequent } \\
(\mathrm{n}=147)\end{array}$ & $\begin{array}{l}\text { never } \\
(\mathrm{n}=24)\end{array}$ & $\begin{array}{l}\text { infrequent } \\
(\mathrm{n}=66)\end{array}$ & $\begin{array}{l}\text { frequent } \\
(\mathrm{n}=187)\end{array}$ \\
\hline Global cognitive function & $25.7(0.2)$ & $25.9(0.2)$ & $25.8(0.4)$ & $26.2(0.3)$ & $25.9(0.2)$ & $26.1(0.2)$ & $25.1(0.4)$ & $25.9(0.3)$ & $26.2(0.2)$ \\
\hline Episodic memory & $4.7(0.1)^{*}$ & $4.8(0.1)$ & $4.6(0.2)$ & $5.0(0.1)$ & $5.0(0.1)$ & $5.2(0.1)^{*}$ & $4.5(0.2)$ & $4.9(0.1)$ & $5.1(0.1)^{*}$ \\
\hline Semantic memory & $19.2(0.4)$ & $19.5(0.7)$ & $18.9(1.1)$ & $20.8(0.7)$ & $20.2(0.4)$ & $20.9(0.5)$ & $19.7(1.1)$ & $19.6(0.7)$ & $20.4(0.4)$ \\
\hline Prospective memory & $2.6(0.1)$ & $2.6(0.1)$ & $2.7(0.2)$ & $2.6(0.1)$ & $2.7(0.1)$ & $2.8(0.1)$ & $2.5(0.2)$ & $2.6(0.1)$ & $2.8(0.1)$ \\
\hline Subjective memory & $2.1(0.0)$ & $2.1(0.0)$ & $2.1(0.1)$ & $2.0(0.1)$ & $2.1(0.0)$ & $2.1(0.0)$ & $2.1(0.1)$ & $2.1(0.1)$ & $2.1(0.0)$ \\
\hline Executive function & $44.9(1.7)^{\mathrm{a}}$ & $43.6(2.7)$ & $38.0(4.1)$ & $36.9(2.8)$ & $37.7(1.7)^{\mathrm{a}}$ & $18.0(1.9)$ & $44.4(4.4)$ & $40.2(2.7)$ & $39.4(1.7)$ \\
\hline Psychomotor speed & $-0.12(0.1)^{*}$ & $-0.08(0.1)$ & $-0.19(0.1)$ & $-0.12(0.1)$ & $0.15(0.1)^{*}$ & $0.17(0.1)^{*}$ & $-0.26(0.1)$ & $0.11(0.1)$ & $0.18(0.1)^{*}$ \\
\hline
\end{tabular}

Values are adjusted mean scores (SE) from covariance analyses. Groups that differ from each other are printed in bold.

${ }^{a} \mathrm{p}<0.10{ }^{*} \mathrm{p}<0.05$. In the cognitive tests used, the higher result means better performance, except for the subjective memory and executive function, where the lowest result is the best performance. Bonferroni adjustment was used for multiple comparisons. Model adjusted for age, sex, education, and follow-up time.

Table 5. Weekly consumption of different alcoholic beverages at midlife and the cognitive function in late life (sample 1982/1987)

\begin{tabular}{|c|c|c|c|c|c|c|c|c|c|}
\hline & \multicolumn{3}{|c|}{ Beer intake } & \multicolumn{3}{|c|}{ Wine intake } & \multicolumn{3}{|c|}{ Spirit intake } \\
\hline & $\begin{array}{l}\text { no } \\
(\mathrm{n}=258)\end{array}$ & $\begin{array}{l}\text { low } \\
(n=38)\end{array}$ & $\begin{array}{l}\text { high } \\
(n=17)\end{array}$ & $\begin{array}{l}\text { no } \\
(\mathrm{n}=245)\end{array}$ & $\begin{array}{l}\text { low } \\
(n=53)\end{array}$ & $\begin{array}{l}\text { high } \\
(\mathrm{n}=15)\end{array}$ & $\begin{array}{l}\text { no } \\
(n=230)\end{array}$ & $\begin{array}{l}\text { low } \\
(n=46)\end{array}$ & $\begin{array}{l}\text { high } \\
(\mathrm{n}=37)\end{array}$ \\
\hline Global cognitive function & $26.1(0.2)$ & $26.3(0.3)$ & $26.2(0.5)$ & $26.3(0.2)$ & $26.2(0.3)$ & $26.1(0.5)$ & $26.2(0.3)$ & $26.1(0.3)$ & $26.3(0.4)$ \\
\hline Episodic memory & $5.0(0.1)$ & $4.8(0.2)$ & $4.8(0.3)$ & $5.0(0.1)$ & $5.0(0.2)$ & $4.7(0.3)$ & $4.8(0.2)$ & $5.1(0.2)$ & $4.8(0.2)$ \\
\hline Semantic memory & $20.9(0.7)$ & $21.4(1.0)$ & $19.7(1.6)$ & $20.5(0.8)$ & $21.7(1.0)$ & $19.9(1.5)$ & $19.9(0.8)$ & $20.9(1.1)$ & $21.3(1.2)$ \\
\hline Prospective memory & $2.7(0.1)$ & $2.5(0.1)$ & $2.6(0.2)$ & $2.8(0.1)$ & $2.6(0.1)$ & $2.4(0.2)$ & $2.5(0.1)$ & $2.7(0.2)$ & $2.6(0.2)$ \\
\hline Subjective memory & $2.1(0.1)$ & $2.1(0.1)$ & $2.2(0.1)$ & $2.1(0.1)$ & $2.1(0.1)$ & $2.2(0.1)$ & $2.2(0.1)$ & $2.2(0.1)$ & $2.0(0.1)$ \\
\hline Executive function & $43.3(3.0)$ & $43.6(4.1)$ & $42.4(6.4)$ & $40.8(3.0)$ & $44.7(3.9)$ & $43.7(6.0)$ & $41.7(3.2)$ & $43.6(4.3)$ & $44.0(4.6)$ \\
\hline Psychomotor speed & $0.07(0.1)$ & $0.19(0.1)$ & $0.15(0.2)$ & $0.12(0.1)$ & $0.34(0.1)$ & $-0.05(0.2)$ & $0.14(0.1)$ & $0.14(0.1)$ & $0.12(0.1)$ \\
\hline
\end{tabular}

Values are adjusted mean scores (SE) from covariance analyses.

All differences between groups were $\mathrm{p}>0.10$. In the cognitive tests used, the higher result means better performance, except for the subjective memory and executive function, where the lowest result is the best performance. Bonferroni adjustment was used for multiple comparisons. Model adjusted for other beverage types, age, sex, education, and follow-up time.

ences were not significant. We repeated the analyses with full adjustments and excluded persons who had quit drinking: persons who were never drinkers at both time points still had a poorer executive function as compared with those who were infrequent drinkers on both occasions $(\mathrm{p}=0.02)$.

Alcohol Types, Quantity of Alcohol Drunk in Midlife (in 1982 and 1987) and in Late Life (1998), and

Cognitive Functions in Late Life

We could obtain more detailed information of midlife alcohol drinking from those subjects who were included in the CAIDE study in 1982 and 1987 ( $\mathrm{n}=369$ ), and, therefore, we conducted secondary analyses in this smaller group. The majority of the participants reported that they had not drunk beer $(83 \%)$, wine $(78 \%)$, or spirits (73\%) during the previous week. Among women, it was more frequent to report that they had not drunk any alcoholic beverages during the previous week than among men (70 vs. $35 \%)$. Most of those who had drunk beer drunk one or two bottles (69\%), and the maximal consumption was 14 bottles/week. The majority of wine drinkers drank one to two glasses (77\%), and 55\% of the spirit drinkers had drunk one to two drinks. 
For the corresponding late-life analyses, similarly, only the persons who had had their baseline examination in 1982 and 1987 were included. The majority of the participants reported at the late-life examination that they had not drunk beer $(82 \%)$, wine $(78 \%)$, or spirits $(72 \%)$ during the previous week.

Drinking of wine, beer, or spirits (weekly consumption divided into nondrinkers and drinkers with low and high consumption from the median value) at midlife (table 5) or in late life was not associated with any of the cognitive functions in the analyses adjusted for other beverage types, age, sex, education, and follow-up time. The total weekly alcohol drinking at midlife or in late life (all alcohol types combined, categorized into three groups) was not associated with any of the cognitive functions investigated.

A total of 84 participants reported that they had quit drinking any time prior to the 1998 examination. The quitters had a poorer performance in psychomotor speed $(p=0.00)$ in the analyses adjusted for sociodemographic variables, but this difference was no longer significant, when full adjustment was applied.

\section{Nonparticipants}

The nonparticipants $(\mathrm{n}=542)$ of the follow-up visit were older, less educated, and had higher systolic and diastolic blood pressures, total serum cholesterol levels, and body mass index values, and they were more often smokers at midlife than the participants $(n=1,341)$. There were equal proportions of men and women among nonparticipants and participants. The midlife alcohol drinking frequency was similar in the two groups. The nonparticipants drank more beer than the participants, but both groups drank equal amounts of wine and spirits.

\section{Discussion}

Our study investigated the relationship between midlife alcohol drinking and late-life cognitive functions as well as between late-life alcohol drinking and late-life cognitive functions. The nondrinkers had a poorer cognitive performance than drinkers, especially in the domains related to fluid intelligence, i.e., executive function, psychomotor speed, as well as episodic memory, whereas the other cognitive functions showed little association with alcohol drinking.

Our results are in accordance with some of the earlier findings showing that moderate drinkers perform better in certain domains of cognition [5-7, 11-18]. Interesting- ly, this type of relation has been found in different populations with respect to their alcohol drinking, and with varying definitions of moderate drinking. This may indicate that perhaps moderate lifestyles in general, which can vary across cultural environments, can protect from cognitive deterioration. Alcohol drinking might be an indicator of a more complex pattern of social and lifestyle factors which may be difficult to determine exactly. For example, moderate alcohol drinkers may have psychosocial benefits [38]. Another possibility is that the dose-effect discrepancy would be due to a large underreporting of alcohol drinking in certain populations.

The role of alcohol drinking for the cognitive functions might be somewhat different at different time points. At both midlife and late life examinations, the never drinkers had a poorer performance in several cognitive domains than drinkers. The late-life frequent drinkers had a better performance than the infrequent drinkers in episodic and prospective memory, whereas the midlife frequent and infrequent drinkers did not differ from each other in any of the cognitive domains. One explanation can be that the persons who were frequent drinkers still in late life were in better health. The adjustment for the presence of several cardiovascular risk factors and diseases did not eliminate these results. However, it is possible that there still is some residual confounding related to a greater morbidity among the never drinkers and the infrequent drinkers. Another possibility is a 'reverse causation', i.e., that at old age the persons with cognitive problems have stopped or reduced their alcohol consumption, leading to a falsely positive association between old-age frequent alcohol consumption and cognitive functioning. Accordingly, we observed that the persons who reported in late life that they had quit drinking had a somewhat poorer performance. Demented persons were excluded from our analyses, but probably there were persons with preclinical dementia in the sample. If people with preclinical dementia were those who had reduced their drinking (or forgot what and how much they had drunk), then the finding that never drinkers had a poorer performance than frequent drinkers in a dementia-free population would be somewhat overestimated.

The mechanisms behind the association between alcohol drinking and cognitive functions are not known. The fact that alcohol drinking especially influenced measures of psychomotor speed, episodic memory, and executive function may suggest that white mater abnormalities would play a role [39]. In fact, alcohol drinking has been associated with fewer brain infarcts and was shown to have a $U$ shape relationship with white matter 
lesions [40]. White matter changes and infarcts, in turn, may reflect a vascular mechanism responsible for the observed association between alcohol and cognitive functions [41]. Alcohol has a beneficial effect on several cardiovascular risk factors, including hypertension, lipid and lipoprotein levels, and inflammatory and hemostatic factors [42], some of which are possible risk factors for poor cognitive function and dementia [43]. In our study, we adjusted the analyses for several cardiovascular risk factors and diseases, but we did not have information on all factors. In addition to cardiovascular effects, moderate amounts of alcohol could also act directly by releasing acetylcholine in the hippocampus [44], thereby affecting cognitive functions. Some studies have proposed that the protective effect of alcohol would be due to the effect of specific antioxidant substances in wine [45]. This can hardly explain the results obtained in our study, since the most typically consumed alcohol types in Finland at the time of the study were beer and spirits. Further, the associations found for specific alcohol types showed no clear pattern for one type being better than others.

Curiously, we found that the effect of drinking appeared almost exclusively among the nonsmokers, and there were statistical interactions between smoking and alcohol for episodic memory and psychomotor speed. Smoking is associated with increased oxidative stress [46], has a deleterious effect on cerebral vasculature and circulation [47], and increases the risk of stroke [48]. Thus one could hypothesize that these factors cancel the possible benefits of alcohol among the smokers. Another hypothesis is that perhaps there were more heavy drinkers among the smokers, and, therefore, the negative effects of heavy drinking would lead to nonsignificant results among the smokers. Further, it is also possible that we observed no effect among the smokers due to too few smokers among the never drinkers.

The study has several strengths: First, there are population-based data with high participation rates which increases the reliability of the results. We had the advantage to have the information on alcohol drinking both at midlife and in late life. This permits us to investigate whether the effect of alcohol is the same at different time points in life. Also, we had the possibility to investigate whether a change in the drinking frequency is associated with cognitive functions. Furthermore, we had data on several domains of cognitive function which has been the case in only a few previous studies. The limitation of most studies concerning alcohol consumption is the reliability of the alcohol consumption data. Our analyses are based on self-reporting of the subjects, and it is likely that some subjects had drunk more alcohol than what they reported. However, this should bias our results only, if the difference between actual and reported alcohol consumption was depending on the cognitive function of the subjects. At the time of the midlife assessment, we assumed that most of our subjects were cognitively fairly intact. Thus at least the analyses of midlife alcohol consumption and of late-life cognition would not be biased by errors in reporting of the alcohol consumption. It would have been interesting to study whether alcohol drinking is associated with changes in cognitive performance over time, but unfortunately we did not have information on participants' cognitive performance at baseline. In the subanalyses among ApoE4 carriers, and among men, as well as in the analyses of beverage-specific differences and in the interaction analyses, we may have had negative results due to insufficient power. The fact that we showed differences according to alcohol drinking frequency in some domains of cognitive function but not in others may be due to true differences in associations, but may be partially accounted for also by the fact that some of the tests (e.g., MMSE) were less sensitive to detect differences. Finally, the differences in the test results between the groups with best and poorest performance were not very large. All participants were nondemented, and their cognitive functioning thereby within normal limits. It is difficult to estimate what is the impact of such small cognitive differences in an individual's quality of life.

Our results indicate that alcohol drinking both at midlife and in late life may be associated with several cognitive functions, including episodic memory, executive function, and psychomotor speed, in late life. However, the mechanisms that convey the effect of alcohol on cognitive functions are not known, and why certain groups (nonsmokers) get more benefit from moderate alcohol drinking than others remains to be investigated. Furthermore, we cannot exclude the possibility that it would not be the effect of alcohol per se, but that other social and lifestyle-related factors that go together with certain drinking habits are the reason behind the favorable association between alcohol drinking and cognition. We agree with the previous conclusions that there is no indication that moderate alcohol drinking would be harmful to the cognition. However, at the moment, it is not possible to define a specific beneficial level of alcohol intake in relation to cognitive functions. Taking into account the well-known harms related to heavy alcohol drinking and the lack of long-term follow-up 
studies or randomized controlled trials with consecutive assessment of changes in various cognitive domains, it would be too early to recommend alcohol to nondrinkers.

\section{Acknowledgment}

We thank our colleagues from the Cardiovascular Risk Factors, Aging and Dementia (CAIDE) Study Group for their cooperation in data collection and management.

\section{References}

$\checkmark 1$ Horn JL, Cattell RB: Age differences in fluid and crystallized intelligence. Acta Psychol (Amst) 1967;26:107-129.

2 Christensen H: What cognitive changes can be expected with normal ageing? Aust N Z J Psychiatry 2001;35:768-775.

3 Dufouil C, Tzourio C, Brayne C, Berr C, Amouyel P, Alperovitch A: Influence of apolipoprotein E genotype on the risk of cognitive deterioration in moderate drinkers and smokers. Epidemiology 2000;11:280-284.

-4 Leibovici D, Ritchie K, Ledesert B, Touchon $\mathrm{J}$ : The effects of wine and tobacco consumption on cognitive performance in the elderly: a longitudinal study of relative risk. Int J Epidemiol 1999;28:77-81.

-5 Espeland MA, Gu L, Masaki KH, Langer RD, Coker LH, Stefanick ML, Ockene J, Rapp SR: Association between reported alcohol intake and cognition: results from the Women's Health Initiative Memory Study. Am J Epidemiol 2005;161:228-238.

-6 Stampfer MJ, Kang JH, Chen J, Cherry R, Grodstein F: Effects of moderate alcohol consumption on cognitive function in women. N Engl J Med 2005;352:245-253.

$\checkmark 7$ Hébert LE, Scherr PA, Beckett LA, Albert MS, Rosner B, Taylor JO, Evans DA: Relation of smoking and low-to-moderate alcohol consumption to change in cognitive function: a longitudinal study in a defined community of older persons. Am J Epidemiol 1993;137:881-891.

-8 Cervilla JA, Prince M, Mann A: Smoking, drinking, and incident cognitive impairment: a cohort community based study included in the Gospel Oak Project. J Neurol Neurosurg Psychiatry 2000;68:622-626.

-9 Launer LJ, Feskens EJ, Kalmijn S, Kromhout D: Smoking, drinking, and thinking. The Zutphen Elderly Study. Am J Epidemiol 1996;143:219-227.

-10 Christian JC, Reed T, Carmelli D, Page WF, Norton JA Jr, Breitner JC: Self-reported alcohol intake and cognition in aging twins. J Stud Alcohol 1995;56:414-416.

-11 Galanis DJ, Joseph C, Masaki KH, Petrovitch H, Ross GW, White L: A longitudinal study of drinking and cognitive performance in elderly Japanese American men: the Honolulu-Asia Aging Study. Am J Public Health 2000;90:1254-1259.
2 Kalmijn S, van Boxtel MP, Verschuren MW, Jolles J, Launer LJ: Cigarette smoking and alcohol consumption in relation to cognitive performance in middle age. Am J Epidemiol 2002;156:936-944.

13 Carmelli D, Swan GE, Reed T, Schellenberg GD, Christian JC: The effect of apolipoprotein E epsilon4 in the relationships of smoking and drinking to cognitive function. Neuroepidemiology 1999;18:125-133.

14 Zhou H, Deng J, Li J, Wang Y, Zhang M, He $\mathrm{H}$ : Study of the relationship between cigarette smoking, alcohol drinking and cognitive impairment among elderly people in China. Age Ageing 2003;32:205-210.

15 Bond GE, Burr R, McCurry SM, Graves AB, Larson EB: Alcohol, aging, and cognitive performance in a cohort of Japanese Americans aged 65 and older: the Kame Project. Int Psychogeriatr 2001;13:207-223.

16 Elias PK, Elias MF, D’Agostino RB, Silbershatz H, Wolf PA: Alcohol consumption and cognitive performance in the Framingham Heart Study. Am J Epidemiol 1999;150:580589.

$\checkmark 17$ Dufouil C, Ducimetière P, Alperovitch A: Sex differences in the association between alcohol consumption and cognitive performance. EVA Study Group. Epidemiology of Vascular Aging. Am J Epidemiol 1997;146: 405-412.

18 DeCarli C, Miller BL, Swan GE, Reed T, Wolf PA, Carmelli D: Cerebrovascular and brain morphologic correlates of mild cognitive impairment in the National Heart, Lung, and Blood Institute Twin Study. Arch Neurol 2001;58:643-647.

-19 Schinka JA, Vanderploeg RD, Rogish M, Graves AB, Mortimer JA, Ordoric PI: Effects of the use of alcohol and cigarettes on cognition in elderly adults. J Int Neuropsychol Soc 2002;8:811-818.

20 Elwood PC, Gallacher JE, Hopkinson CA, Pickering J, Rabbitt P, Stollery B, Brayne C, Huppert FA, Bayer A: Smoking, drinking, and other life style factors and cognitive function in men in the Caerphilly Cohort. J Epidemiol Community Health 1999;53:9-14.

21 Anttila T, Helkala EL, Viitanen M, Kareholt I, Fratiglioni L, Winblad B, Soininen H, Tuomilehto J, Nissinen A, Kivipelto M: Alcohol drinking in middle age and subsequent risk of mild cognitive impairment and dementia in old age: a prospective population based study. BMJ 2004;329:539.
22 Ruitenberg A, van Swieten JC, Witteman JC, Mehta KM, van Duijn CM, Hofman A, Breteler MM: Alcohol consumption and risk of dementia: the Rotterdam Study. Lancet 2002; 359:281-286.

23 Orgogozo JM, Dartigues JF, Lafont S, Letenneur L, Commenges D, Salamon R, Renaud $\mathrm{S}$, Breteler MB: Wine consumption and dementia in the elderly: a prospective community study in the Bordeaux area. Rev Neurol (Paris) 1997;153:185-192.

24 Vartiainen E, Puska P, Jousilahti P, Korhonen HJ, Tuomilehto J, Nissinen A: Twentyyear trends in coronary risk factors in north Karelia and in other areas of Finland. Int J Epidemiol 1994;23:495-504.

25 Kivipelto M, Helkala EL, Hanninen T, Laakso MP, Hallikainen M, Alhainen K, Soininen $\mathrm{H}$, Tuomilehto J, Nissinen A: Midlife vascular risk factors and late-life mild cognitive impairment: a population-based study. Neurology 2001;56:1683-1689.

26 The World Health Organization MONICA Project (monitoring trends and determinants in cardiovascular disease): A major international collaboration. WHO MONICA Project Principal Investigators. J Clin Epidemiol 1988;41:105-114.

27 Tsukamoto K, Watanabe T, Matsushima T, Kinoshita M, Kato H, Hashimoto Y, Kurokawa K, Teramoto T: Determination by PCRRFLP of apo E genotype in a Japanese population. J Lab Clin Med 1993;121:598-602.

28 Folstein MF, Folstein SE, McHugh PR: 'Minimental state'. A practical method for grading the cognitive state of patients for the clinician. J Psychiatr Res 1975;12:189-198.

29 Heun R, Burkart M, Wolf C, Benkert O: Effect of presentation rate on word list learning in patients with dementia of the Alzheimer type. Dement Geriatr Cogn Disord 1998;9: 214-218.

30 Nyberg L, Nilsson LG, Olofsson U, Backman L: Effects of division of attention during encoding and retrieval on age differences in episodic memory. Exp Aging Res 1997;23: 137-143.

-31 Borkowski JG, Benton AL, Spreen O: Word fluency and brain damage. Neuropsychologia 1967;5:135-140.

32 Tiffin J: Purdue Pegboard Examiner's Manual. Rosemont, London House Press, 1968.

33 Wechsler D: Wechsler Adult Intelligence Scale Manual. New York, Psychological Corporation, 1944. 
-34 Stroop JR: Studies of inference in serial verbal reaction. J Exp Psychol 1935;18:643662 .

-35 Einstein GO, Smith RE, McDaniel MA, Shaw $P$ : Aging and prospective memory: the influence of increased task demands at encoding and retrieval. Psychol Aging 1997;12:479488.

36 Bennett-Levy J, Powell GE: The subjective memory questionnaire (SMQ). An investigation into the self-reporting 'real-life' memory skills. Br J Soc Clin Psychol 1980;19:177188.

-37 Beck AT, Ward CH, Mendelson M, Mock J, Erbaugh J: An inventory for measuring depression. Arch Gen Psychiatry 1961;4:561571.

-38 Peele S, Brodsky A: Exploring psychological benefits associated with moderate alcohol use: a necessary corrective to assessments of drinking outcomes? Drug Alcohol Depend 2000;60:221-247.

>39 Gunning-Dixon FM, Raz N: The cognitive correlates of white matter abnormalities in normal aging: a quantitative review. Neuropsychology 2000;14:224-232.
40 Mukamal KJ, Longstreth WT Jr, Mittleman MA, Crum RM, Siscovick DS: Alcohol consumption and subclinical findings on magnetic resonance imaging of the brain in older adults: the cardiovascular health study. Stroke 2001;32:1939-1946.

41 van Dijk EJ, Breteler MM, Schmidt R, Berger K, Nilsson LG, Oudkerk M, Pajak A, Sans S, de Ridder M, Dufouil C, Fuhrer R, Giampaoli S, Launer LJ, Hofman A: The association between blood pressure, hypertension, and cerebral white matter lesions: cardiovascular determinants of dementia study. Hypertension 2004;44:625-630.

42 Hill JA: In vino veritas: alcohol and heart disease. Am J Med Sci 2005;329:124-135.

43 Fillit HM, Butler RN, O'Connell AW, Albert MS, Birren JE, Cotman CW, Greenough WT, Gold PE, Kramer AF, Kuller LH, Perls TT, Sahagan BG, Tully T: Achieving and maintaining cognitive vitality with aging. Mayo Clin Proc 2002;77:681-696.
44 Stancampiano R, Carta M, Cocco S, Curreli R, Rossetti ZL, Fadda F: Biphasic effects of ethanol on acetylcholine release in the rat prefrontal cortex. Brain Res 2004;997:128132.

45 Truelsen T, Thudium D, Gronbaek M: Amount and type of alcohol and risk of dementia: the Copenhagen City Heart Study. Neurology 2002;59:1313-1319.

46 Polidori MC, Mecocci P, Stahl W, Sies H: Cigarette smoking cessation increases plasma levels of several antioxidant micronutrients and improves resistance towards oxidative challenge. Br J Nutr 2003;90:147-150.

47 Terborg C, Bramer S, Weiller C, Rother J: Short-term effect of cigarette smoking on $\mathrm{CO}_{2}$-induced vasomotor reactivity in man: a study with near-infrared spectroscopy and transcranial Doppler sonography. J Neurol Sci 2002;205:15-20.

48 Tuomilehto J, Bonita R, Stewart A, Nissinen A, Salonen JT: Hypertension, cigarette smoking, and the decline in stroke incidence in eastern Finland. Stroke 1991;22:7-11. 